\title{
COMO PODE UM PEIXE VIVO VIVER FORA DO BRASIL? O CASO PEIXONAUTA
}

\section{RESUMO}

Este trabalho propõe demonstrar, por meio de um estudo de caso, como uma pequena empresa brasileira da indústria de animação operacionalizou a produção e comercialização nacional e internacional, com exportação para mais de 60 países, de seu produto: a serie Peixonauta. O Brasil, historicamente consumidor des ses produtos, não desenvolveu sua indústria de animação. A TV Pinguim operacionalizou uma alternativa a esta situação demonstrando que é possível produzir localmente animações de qualidade internacional. A pesquisa demonstrou que a empresa baseou suas competências estratégicas na condução do projeto considerando a manutenção do foco na atividade de criação e, principalmente, na capacidade de identificar, utilizar e influenciar fatores governamentais e de mercado, imersos em seu ambiente contextual de referência. Para tanto, apresentamos os conceitos de Pilares Institucionais e Internacionalização, pois consideramos que a compreensão destes conceitos proporciona uma base solida para gestores de pequenas empresas que pretendem internacionalizar seus produtos. Também entendemos que a conceptualização teórica e o caso apresentado contribuem para que os gestores de pequenas empresas aumentem sua percepção de oportunidades institucionais e governamentais que cercam seus negócios.

Palavras-chave: Indústria de Animações; Estratégia para Pequenas Empresas; Estudo de Caso; Pilares Institucionais; Internacionalização.

\section{HOW CAN A LIVE FISH LIVE OUT OF BRAZIL? THE CASE OF PEIXONAUTA}

\section{ABSTRACT}

This paper proposes to demonstrate, through a case study, how a small Brazilian company of animation industry operationalized the national and international production and commercialization, exporting to more than 60 countries, your product: the Peixonauta series. The Brazil, historically a consumer of these products, has not developed its animation industry. The TV Pinguim operationalized an alternative to this situation showing that it is possible to produce locally animation with international quality. The research has shown that the organization based their strategic competences in the conduct of the project considering the maintenance of focus on the creation activity and, mainly, on the capacity to identify, uses and influence governmental and market factors, embedded in its contextual environment of reference. For that, we present the concepts of Institutional Pillars and Internationalization, because we consider that the understanding of these concepts provides a solid basis for managers of small companies that intend to internationalize their products. We also understand that the theoretical conceptualization and the case contribute to the managers of small companies to increase their perception of institutional and governmental opportunities that their businesses are embedded.

Keywords: Animation Industry; Small Business Strategy; Case Study, Pillars of Institutions; Internationalization . 


\section{¿CÓMO PUEDE UN PECHO VIVO VIVIR FUERA DEL BRASIL? EL CASO PEIXONAUTA}

\section{RESUMEN}

Este trabajo propone demostrar, por medio de un estudio de caso, como una pequeña empresa brasileña de la industria de animación operacionalizó la producción y comercialización nacional e internacional, con exportación a más de 60 países, de su producto: la serie Peixonauta. Brasil, históricamente consumidor de estos productos, no desarrolló su industria de animación. La TV Pingüino ha operado una alternativa a esta situación demostrando que es posible producir localmente animaciones de calidad internacional. La investigación demostró que la empresa basó sus competencias estratégicas en la conducción del proyecto considerando el mantenimiento del foco en la actividad de creación y, principalmente, en la capacidad de identificar, utilizar e influenciar factores gubernamentales y de mercado, inmersos en su ambiente contextual de referencia. Para ello, presentamos los conceptos de Pilares Institucionales e Internacionalización, pues consideramos que la comprensión de estos conceptos proporciona una base sólida para gestores de pequeñas empresas que pretenden internacionalizar sus productos. También entendemos que la conceptualización teórica y el caso presentado contribuyen a que los gestores de pequeñas empresas aumenten su percepción de oportunidades institucionales y gubernamentales que rodean sus negocios.

Palabras clave: Industria de Animaciones; Estrategia para Pequeñas Empresas; Estudio de caso; Pilares Institucionales; Internacionalización.

\footnotetext{
${ }^{1}$ Doutor em Administração pela Universidade de São Paulo - USP. Doutorando em Learning Sciences at University of Calgary, Werklund School of Education, Canadá. Brasil. E-mail: gatti.wilian@gmail.com

2 Doutor em Administração pela Universidade Nove de Julho - UNINOVE. Pós-doutorando em Estratégia Organizacional pelo globADVANTAGE - Center of Research in International Business \& Strategy. ESTG - Instituto Politécnico de Leiria, Portugal. Brasil. E-mail: profmarcioluiz@uol.com.br
} 


\section{INTRODUÇÃO}

O mercado de animações para a televisão movimenta milhões de dólares ao redor do mundo. Apesar de estar em franco crescimento o Brasil, até meados de 2006/2007, não tinha condições de produzir as animações em preços e velocidade compatível como mercado internacional. As animações, tanto da televisão aberta quanto por assinatura no Brasil, eram exclusivamente produções internacionais, principalmente, dominadas por produtoras dos Estados Unidos e Canadá. No entanto, esse cenário sofreu uma transformação com o aparecimento de coproduções brasileiras sobressaindo-se a animação "Peixonauta". A produção sobressaiu-se não somente por ter sido líder de audiência no canal infantil Discovery Kids, mas por ser uma produção exclusivamente brasileira desenvolvida e gerenciada por uma produtora de porte pequeno em termos internacionais, a TV Pinguim (Gatti Jr, Gonçalves e Barbosa, 2014).

O problema prático de pesquisa deste estudo parte do pressuposto que o Brasil não possuía tradição em elaborar produções de animação devido a diversos fatores restritivos como, por exemplo, restrições técnicas e tecnológicas de estúdios, pessoal ou tecnologia apropriada ou por questões governamentais como falta de apoio econômico para este tipo de projeto (Gatti Jr, Gonçalves e Barbosa, 2014). Destarte, nossa pergunta de pesquisa se baseia em Como a TV Pinguim produziu animações utilizando estratégias vinculadas ao seu contexto institucional de referência e internacionalizou seus produtos? Para respondermos a esta pergunta a proposta deste estudo é a de um relato técnico que é definido por Biancolino, et al. (2012) como o produto final de um trabalho (pesquisa aplicada ou produção técnica) que descreve uma experiência nas organizações. Este relato técnico evidenciou alguns dos elementos institucionais que alavancaram as estratégias de produção das animações e a posterior internacionalização dos produtos da organização. Para isto, utilizamos o método do estudo de caso (Yin, 2001) empregando a técnica de entrevista semiestruturada em profundidade, junto sócia fundadora da TV Pinguim.

Os resultados obtidos pelo estudo sugeremque a empresa de animação, mesmo diante de um cenário desfavorável, utilizou estratégias ligadas ao seu contexto institucional de referência para produzir e comercializar, em nível nacional e internacional, seu produto. Estas estratégias vincularam-se a órgãos governamentais e de mercado que possibilitaram a alavancagem de recursos para o projeto. Os resultados, também sugerem que, mesmo diante de organismos governamentais burocráticos, é possível que pequenas empresas se utilizem de subsídios do governo em conjunto com os de mercado, ao qual a organização está imersa, para a operacionalização e expansão de seus negócios.

\section{REFERENCIAL TEÓRICO}

\section{Pilares Institucionais e Internacionalização}

O estudo deita-se sobre dois pressupostos teóricos, a Teoria Institucional e a Internacionalização.

A primeira parte explica que a Teoria Institucional tem raízes nas ciências políticas, sociologia e economia, sendo objeto de estudo na Administração há algumas décadas. Ela, de maneira geral, estuda a adoção de práticas e estratégias das organizações e tem como questão central a discussão da legitimação do curso da ação por parte dos atores dentro de um sistema construído e aceito socialmente. A manutenção desse espaço, na perspectiva institucional, fornece a organização elementos de sustentação e sobrevivência influenciando seu desempenho em uma perspectiva longitudinal de durabilidade dinâmica condicionada pelo contexto institucional ao que a organização tem como referência (Rossoni e Machado da Silva, 2008, Quinello, 2007; Machado-da-Silva e Fernandes, 1999).

As organizações, para sua sobrevivência, tendem a buscar recursos vinculados às suas necessidades sociais e econômicas por meio da definição de suas estratégias de ação, orientando-se pelo contexto institucional no plano que mais se adapta com sua lógica interior. Nas situações de busca de desempenho maior ou adaptação a contextos de insegurança a sobrevivência, as organizações estão propensas a adotar mudanças estratégicas de caráter incremental que figuram como legitimas em seu campo institucional de referencia (Machado-da-Silva e Fernandes 1999). No contexto deste estudo, evidenciamos a adaptação aos pilares institucionais que fomentaram os processos de sobrevivência da organização.

A relação entre os elementos organizacionais e institucionais pode ser representada pelo modelo dos Pilares Institucionais proposto por Scott (2008). A estrutura de relações se assenta sobre três pilares: i) regulativo; ii) normativo; e iii) cognitivo-cultural. Estas dimensões, além de destacarem a natureza simbólica dos elementos institucionais evidenciam, também, a influência do comportamento social por meio do modo como estão implicados nas ações, relações e recursos disponíveis no contexto de referencia das organizações.

De forma resumida, sobre o Pilar Regulativo, as instituições restringem e regularizam o comportamento social, assim o processo regulatório envolve a capacidade de estabelecer regras e leis, inspecionar a conformidade dos atores sociais com as mesmas e, quando necessário, manipular sanções - recompensas ou punições - numa tentativa de influenciar comportamentos futuros. Como resultado a legitimação institucional está ligada à capacidade organizacional de se adaptar, ou não, aos aspectos sancionados legalmente. O Pilar Normativo enfatiza os sistemas de 
normativas que incluem valores e normas e introduzem uma dimensão prescritiva, avaliativa e obrigatória na vida social. Valores são concepções do preferido ou desejável, juntamente com a construção de padrões aos quais as estruturas ou comportamentos existentes podem ser comparados e avaliados. As normas especificam o que deve ser feito definindo-se meios legítimos para buscar fins valiosos. Emoutras palavras, o sistema normativo não somente define as regras e os objetivos, mas também designa os caminhos apropriados para persegui-los valorizando os padrões de conduta que sustentam a legitimidade organizacional. O Pilar Cognitivo-Cultural se constitui sobre as concepções compartilhadas que formam a natureza da realidade social e os quadros através dos quais o significado é elaborado. A teoria institucional promove a primazia sobre as dimensões cognitivas da existência humana por meio da mediação entre o mundo externo dos estímulos e a resposta do organismo individual. Estas coleções de representações simbólicas internalizadas do mundo promovem a construção social da realidade que se traduz como um conjunto de conhecimentos culturalmente difundidos e socialmente aceitos que constituem diretrizes para aquilo que os atores sociais idealizam como realidade e que influencia sua própria identidade. Neste processo os elementos considerados conceitualmente $\mathrm{e}$ culturalmente corretos fundamentam a legitimidade organizacional (Scott, 2008). Finalmente, Vermeulen, Van Den Bosch e Volberda (2007) observaram que procedimentos, regras, sanções e leis (forças regulativas), valores, certificados e normas (forças normativas) e crenças e significados (forças culturalcognitivas) seriam elementos-chave para se compreender as inter-relações e os impactos da ação estratégica nas organizações.

O segundo pressuposto do estudo explica que a internacionalização de uma organização ocorre quando a mesma passa a ter seus bens e/ou serviços representados ou vendidos em mercados externos. Naturalmente, estes processos de internacionalização recebem pressões institucionais dos países de origeme dos países hospedeiros que influenciam os processos de internacionalização destas empresas (Borini e Ferreira, 2015). Em geral, as organizações recorrem às estratégias de internacionalização quando percebem barreiras ou a estagnação de mercado para seus produtos e/ou serviços em seu país de origem. A busca por recursos financeiros e/ou tecnológicos, além de possíveis oportunidades externas, também, esta entre os motivos da internacionalização (Borini e Ferreira, 2015; Cavusgil, Knight e Riesenberger, 2010).

As estratégias de internacionalização dos produtos ocorrem, em geral, de acordo com a estrutura que está vinculada ao negócio da organização. Uma organização que produz bens de consumo como celulares ou máquinas industriais, por exemplo, poderá adotar estratégias que vão desde a exportação de s eus produtos, como optarem por adquirir fábricas de concorrentes em outro país. Por outro lado, uma organização que presta serviços como, por exemplo, um banco ou uma consultoria, ou até mesmo uma produtora de filmes, possivelmente, optarão por estratégias de instalarem filiais em outros países, ou juntarem-se á empresas de serviços similares em outro país (joint-venture), ou ainda licenciar seus produtos para comercialização em outros países (Cavusgil, Knight e Riesenberger, 2010).

Como o foco do nosso estudo é uma produtora na área de animação nos interessa aqui a estratégia de licenciamento internacional. De forma bastante sucinta, o licenciamento internacional consiste na realização de um contrato de licenciamento que especifica a natureza da relação entre o licenciador (empresa proprietária da propriedade intelectual) e o licenciado (usuário). $\mathrm{O}$ licenciamento possibilita ao licenciado a possibilidade de comercializar e produzir um produto semelhante a outro que o licenciado já possui em seu país de origem. O licenciador ao assinar o contrato de concessão passa a ter direito de receber royalties do licenciado. Estes pagamentos variam de acordo com o faturamento bruto gerado a partir da utilização dos ativos licenciados e, em geral, possuem validade especifica de tempo. Finalmente, a maioria das organizações celebra contratos de exclusividade, ou seja, o licenciado não tem permissão de dividir os produtos licenciados com outra empresa dentro de um território pré-estabelecido. Em contra partida, o licenciador concede somente àquele licenciado o direito de exploração do ativo no mesmo território (Cavusgil, Knight e Riesenberger, 2010, p.339-340).

\section{MÉTODO DA PESQUISA}

A pesquisa é qualitativa e utilizamos o método do estudo de caso. O estudo de caso é definido por Yin (2001, p.32) como um método de pesquisa com três características marcantes: a) ser uma investigação empírica que estuda um fenômeno contemporâneo dentro de seu contexto de vida real, no qual os limites entre o fenômeno e o contexto não estão claramente definidos; b) enfrentar uma situação tecnicamente única em que haverá muito mais pontos de interesse do que fontes de dados, exigindo triangulações de evidências; e c) beneficiar-se do desenvolvimento prévio de proposições teóricas para conduzir a coleta e análise de dados.

Desse modo, considerando-se a questão de pesquisa que guia este trabalho a utilização do método de estudo de caso é bastante adequada à definição de Yin (2001, p. 32). Na medida em que a gestão dos serviços de uma produtora brasileira de animações é um fenômeno contemporâneo, no qual os limites entre o fenômeno e o contexto não estão claramente definidos (item a) e cada produtora é tecnicamente única (item b). Yin (2001, p. 61), ainda explica que o estudo de caso único, adotado nesse trabalho, é semelhante a um experimento único, sendo adequado em três situações: a) Caso decisivo para testar uma 
teoria: o caso decisivo ocorre após a teoria ter especificado um conjunto claro de proposições, assim como de circunstâncias nas quais se acredita que tais proposições sejam verdadeiras. Para confirmar, contestar ou estender a teoria deve existir um caso único que satisfaça todas as condições para testar a teoria; b) Caso raro ou extremo: o caso raro ou extremo tem valor justamente pela impossibilidade de uma exploração mais extensiva do fenômeno, dada sua raridade. Assim, o caso único pode fornecer informações e características até então desconhecidas sobre o fenômeno estudado; e c) Caso revelador: o caso revelador ocorre quando o pesquisador tem a oportunidade de estudar um fenômeno previamente inacessível à investigação científica. Assim, quando pesquisadores têm oportunidade de estudar fenômenos que eram predominantemente inacessíveis aos outros cientistas, justifica-se a utilização de um caso único por sua natureza reveladora. O caso Peixonauta enquadrase na categoria do caso raro ou extremo na medida em que, mesmo em termos internacionais, raros são os casos de em que pequenas produtoras de animação conseguem evoluir de forma satisfatória suas produções de animação, principalmente em países sem tradição prévia nesse setor como é o caso do Brasil. Ademais, pode-se considerar também o caso Peixonauta parcialmente como um caso revelador no sentido em que não existiam casos de produtoras brasileiras, em especial no tocante a possuírem um alto grau de internacionalização como é o caso da TV Pinguim.

O caso foi desenvolvido por meio de uma entrevista realizada com sra. Celia Catunda, sócia fundadora da TV Pinguim, na sede da produtora, a qual foi conduzida por roteiro semiestruturado e investigou quatro etapas principais: i) da ideia a constituição da TV Pinguim; ii) da TV Pinguim ao conceito Peixonauta; iii) do conceito ao lançamento; e iv) do lançamento ao sucesso.

\section{O CASO DA TV PINGUIM}

A TV Pinguim foi fundada em 1989 por dois sócios (hoje são três): Celia Catunda e Francisco (Kiko) Mistrorigo. Em seu início era dedicada a produção publicitária, mas seus sócios entendiam que o sucesso só viria com a produção de conteúdo próprio e gerenciamento de marcas e personagens ligados a cultura e imerso em contexto brasileiro. Produziram então alguns programas na TV brasileira:

- 1993: série para pré-escola "Poesias Animadas" para TV Cultura

- 1994: Rita também na TV Cultura

- 2002: De onde vem?

A empresa percebeu como oportunidade de negócios o boom de cartoons nos EUA. Desde 1992 havia um canal exclusivo para animações nos EUA (Cartoon Networks). Aliado a essa percepção, foi instituído o Condecine (Contribuição para o Desenvolvimento da Indústria Cinematográfica) tributo regulamentado em 2001 (artigo 39 da Lei do Audiovisual). Assim uma TV estrangeira pagaria $11 \%$ sobre o lucro de uma produção caso não destine $3 \%$ do seu lucro a uma coprodução com empresa nacional, o qual foi uma conquista da ABPI-TV (Associação Brasileira de Produtoras Independentes de Televisão), incentivando a produção local de animações.

Em 2002 a TV Pinguim visitou as feiras do setor - Marché International des Programmes de Télévision (MIPTV) e Marché International des Programmes de Communication (MIPCOM); ambas em Cannes em busca de parceiros para coprodução. Nas reuniões (pré-agendadas) levou a "bíblia" do Peixonauta, ou seja, seu projeto técnico. Após acertos comerciais, iniciou o projeto de coprodução do Peixonauta com a canadense Nelvana, produtora das animações Os Backyardigans, Franklin, Miss Spider, Babar e as aventuras de Badou, entre outras. No ano seguinte, assinou um pré-contrato com a Discovery Kids, mas a TV Pinguim não possuía todos os recursos para a produção da série de 52 episódios de 11 minutos, cerca de R $\$ 6$ milhões. A coprodução com a Nelvana foi abortada depois de 1 ano de projeto. $\mathrm{O}$ tempo previsto para a produção com os canadenses não atendia aos prazos contratados com a Discovery. Restava ainda a dificuldade para levantar fundos necessários para a finalização do projeto.

Parte do investimento veio da Discovery incentivada pelo artigo 39 da Lei do Audiovisual. Outra parte do patrocínio originou-se da Bunge Alimentos, cerca de R\$ 400 mil. A TV Pinguim buscou a parte restante junto a investidores. Apresentou o projeto a um grupo de investidores de risco em um evento da Financiadora de Estudos e Projetos (FINEP) ligada ao Ministério de Ciência e Tecnologia. Nenhum resultado monetário foi obtido, mas a empresa aprendeu com a experiência, por exemplo, montar um business plan. Um participante do evento, ligado a Ancine (Agência Nacional do Cinema) apresentou a TV Pinguim ao BNDES. Pelo Programa de Apoio à Cadeia Produtiva do Audiovisual (Procult) do BNDES conseguiu o restante do financiamento para produzir a série.

A produção foi realizada em 22 meses. A empresa com 15 funcionários contou com a participação de 150 pessoas para a produção da $1^{\mathrm{a}}$ temporada, a qual estreou no canal Discovery Kids em abril de 2009. Segundo o IBOPE foi no último trimestre de 2010 a terceira atração mais vista no canal atrás de Mister Maker e Mecanimais.

Após o sucesso na Discovery Kids, a TV PingUim, conseguiu licenciar e distribuir o Peixonauta, por meio de parcerias, para mais de 65 países:

- Canadá - TVA Quebec, em francês. 
- Oriente Médio - Canal Al Jazeera, em árabe: Emirados Árabes Unidos, Omã, Kuwait, Bahrain, Qatar, Arábia Saudita, Iraque, Irã, Iêmen, Jordânia, Palestina, Síria, Líbano, Egito, Líbia, Argélia, Tunísia, Marrocos, Sudão, Chade, Djibuti, Mauritânia, Somália.

- Oriente Médio - Canal E-Vision, em inglês: Emirados Árabes Unidos, Omã, Kuwait, Bahrain, Qatar, Arábia Saudita, Iraque, Irã.

- Turquia - Canal Smart HD, em turco.

- América Latina - Discovery Kids, em espanhol, inglês e português: Argentina, Belize, Bolívia, Brasil, Chile, Colômbia, Costa Rica, Equador, El Salvador, Ilhas Falkland, Guiana Francesa, Guatemala, Guiana, Haiti, Honduras, México, Nicarágua, Panamá, Paraguai, Peru, Suriname, Uruguai, Venezuela, Anguilla, Antígua e Barbuda, Aruba, Bahamas, Barbados, Bermuda, Ilhas Virgens Britânicas, Ilhas Caiman, Cuba, Dominica, República Dominicana, Granada, Guadalupe, Haiti, Jamaica, Martinica, Monserrate, Antilhas Holandesas, Porto Rico, Santa Lucia, São Cristovão e Nevis, São
Vicente e Granadinas, Trinidad e Tobago, Turcos e Caicos. Na Venezuela no Canal TVES, TV Aberta.

- TAM Linhas Aéreas - rotas nacionais e internacionais, em inglês e português.

A fim de compreender a evolução da TV Pinguim ficou claro que as competências internas inerentes a organização, tais como gestão de projetos e de produtos, capacidade de manter-se no orçamento estipulado, cumprir prazos de produção, entre outras foram fundamentais, porém apenas qualificadoras. Os verdadeiros pontos de ruptura foram proporcionados pela capacidade da organização em beneficiar-se e, algumas vezes inclusive, influenciar fatores institucionais sem os quais seria impossível obter os resultados que a TV Pinguim conseguiu.

Utilizando-se assim da estrutura conceitual de Scott, (2008) e Vermulen, Van Den Bosch e Volberda (2007), com seus três pilares institucionais, apresentase a seguir o Quadro 1, no qual resume-se a utilização desses pilares pela organização estudada.

\begin{tabular}{|c|c|c|c|}
\hline & Pilar Regulativo & Pilar Normativo & Pilar Cognitivo-Cultural \\
\hline Mecanismos & Leis/Incentivos Fiscais & Associações/Parcerias & $\begin{array}{c}\text { Crenças/Lógicas de } \\
\text { Ação }\end{array}$ \\
\hline Brasil & $\begin{array}{l}\text { 1) Não há barreiras de entrada a } \\
\text { animações estrangeiras no Brasil; } \\
\text { 2) Não há obrigatoriedade de } \\
\text { reinvestimento de lucros das } \\
\text { produtoras internacionais no } \\
\text { Brasil como há na França e } \\
\text { Canadá; } \\
\text { 3) Incentivo fiscal pelo artigo } 39 \\
\text { da lei do áudio visual (2001). }\end{array}$ & $\begin{array}{l}\text { 1) Criação da Associação } \\
\text { de Produtores } \\
\text { Independentes (2000); } \\
\text { 2) Projeto conjunto de } \\
\text { exportação audiovisual com } \\
\text { apoio da Apex, Sebrae e } \\
\text { Ministério da Cultura } \\
\text { (2002); } \\
\text { 3) ANCINE. }\end{array}$ & $\begin{array}{l}\text { 1) O Brasil não possuía } \\
\text { tradição em produção de } \\
\text { animações; } \\
\text { 2) TVs abertas acreditam } \\
\text { que público infantil deseja } \\
\text { animações importadas, } \\
\text { além de adquiri-las a } \\
\text { baixo custo. }\end{array}$ \\
\hline TV Pinguim & $\begin{array}{l}\text { a) Apres entou projeto a FINEP, } \\
\text { apesar não obter financiamento } \\
\text { (não se enquadrou as regras), } \\
\text { conseguiu adquirir experiência. }\end{array}$ & $\begin{array}{l}\text { a) Cons eguiu convencer o } \\
\text { BNDES a criar a linha de } \\
\text { financiamento Procult } \\
\text { (2007); } \\
\text { b) Utilizou a linha do } \\
\text { BNDES para fechar o } \\
\text { pacote de financiamento da } \\
1^{\text {a }} \text { temporada do } \\
\text { Peixonauta.(2009). }\end{array}$ & $\begin{array}{l}\text { a) Convenceu a Discovery } \\
\text { Kids que o Brasil poderia } \\
\text { criar uma animação de } \\
\text { sucesso e fechou contrato } \\
\text { do Peixonauta (2004); } \\
\text { b) Conseguiu convencer } \\
\text { distribuidores } \\
\text { internacionais e o } \\
\text { Peixonauta está em cerca } \\
\text { de } 60 \text { países (2011) }\end{array}$ \\
\hline
\end{tabular}

Quadro 1 - Pilares institucionais que possibilitaram o Peixonauta

Fonte: Elaboração dos autores adaptado de Scott (2008) e Vermeulen, Van Den Bosch e Volberda (2007)

\section{CONSIDERAÇÕES FINAIS}

Este estudo explicou como a TV Pinguim internacionalizou sua produção (o Peixonauta) utilizando estratégias e oportunidades vinculadas ao seu contexto institucional de referência. Com base nos pressupostos das teorias institucional e de internacionalização, e em especial no quadro 1 adaptado a partir três pilares institucionais de Scott (2008) e Vermulen, Van Den Bosch e Volberda (2007), 
foi possível identificar a capacidade de articulação e influencia estratégica da produtora com agentes externos imersos em seu contexto de referência. Neste contexto estavam vinculados órgãos ligados ao Governo Brasileiro e empresas do mercado de animações que figuraram como fatores determinantes para a produção e a comercialização nacional e internacional do produto.

$\mathrm{O}$ ambiente institucional brasileiro era desfavorável à produção de animações, uma vez que animações estrangeiras chegavam ao Brasil a preços muito baixos, sendo forte competidoras a eventuais produtos locais. Soma-se a esta dificuldade contextual a inexistência de uma indústria brasileira no setor de animação que pudesse fomentar a produção nacional e a comercialização das animações. Desse modo, a TV Pinguim demonstrou capacidade de utilizar e influenciar diversos fatores institucionais imersos em seu ambiente contextual de referência a seu favor, de tal como: a) influenciar o BNDES na criação da linha Procult, a qual financiou a produção do Peixonauta; b) convencer a Discovery Kids a investir em uma produção brasileira; c) influenciar, por meio da ABPI$\mathrm{TV}$, a legislação brasileira sobre animações; e d) convencer parceiros estrangeiros a distribuir o Peixonauta em outros países.

A despeito da qualidade de sua produção, a capacidade de articulação interna da TV Pinguim foi determinante para o desempenho da organização. Esta capacidade pode servir de experiência, bem como indicar alguns possíveis caminhos para outras pequenas empresas brasileiras que desejam viabilizar a produção e a comercialização nacional e internacionalização de seus produtos e/ou serviços. Assim, esperamos que este relato técnico possa contribuir gerencialmente para que, pequenas empresas que possuem intenções de expansão de seus negócios, observemsuas capacidades internas, bem como as oportunidades institucionais e governamentais que cercam seus mercados. De certa forma, mesmo com cenários desfavoráveis e sistemas públicos burocráticos, a organização analisada demonstrou ser possível obter recursos de entidades governamentais e, ao mesmo tempo, atuar junto ao seu mercado empresarial para atingir seus objetivos de produção e comercialização.

\section{REFERÊNCIAS}

Biancolino, C. A.; Kniess, C. T. Maccari, E. A.; Rabechini Jr, R. (2012) Protocolo para elaboração de relatos de produção técnica. Revista de Gestão e Projetos - GeP, v.3, n.2.

Borini, F. M. Ferreira, J. (2015) Internacionalização de periódicos científicos brasileiros: estudo de caso à luz da teoria de redes e da teoria institucional. Revista Ibero-Americana de Estratégia - RIAE, v.14, n.4.

Cavusgil, S. T. Knight, G. A. Riesenberger, J. R. (2010) Negócios internacionais: estratégia, gestão e novas realidades. São Paulo: Pearson

Gatti Jr, W.; Gonçalves, M. A.; Barbosa, A. P. F. P. L. (2014) Um estudo exploratório sobre a indústria brasileira de animação para a TV. REAd - Revista Eletrônica de Administração, v.78, n.2.

Machado-da-Silva, C. L. Fernandes, B. H. R. (1999) O impacto da internacionalização nos esquemas interpretativos dos dirigentes do Banco Bamerindus. RAE - Revista de Administração de Empresas, v.39, n.1.

Quinello, R. (2007) A teoria institucional aplicada à Administração. São Paulo: Novatec.

Rossoni, L.; Machado-da-Silva, C. L. (2008) Análise institucional da construção do conhecimento científico em mundos pequenos. FACES R. Adm., v.7, n.1.

Scott, R.W. (2008) Institutions and organizations: Ideas and interest. 3.ed. Thousand Oaks, Sage Publications, Inc.

Vermeulen, P. A. Van Den Bosch, F. A. Volberda, H W. (2007). Complex incremental product innovation in established service firms: A micro institutional perspective. Organization Studies, v.28, n.10

Yin, R. K. (2001) Estudo de Caso: Planejamento e Métodos. Porto Alegre: Bookman. 